\title{
The impact on referrals for a clinical suspicious cervix on a colposcopy department.
}

Dr Kate Glennon, Tallaght University Hospital, Dublin Ireland Dr Gunther Von Banau, Tallaght University Hospital Dublin, Ireland
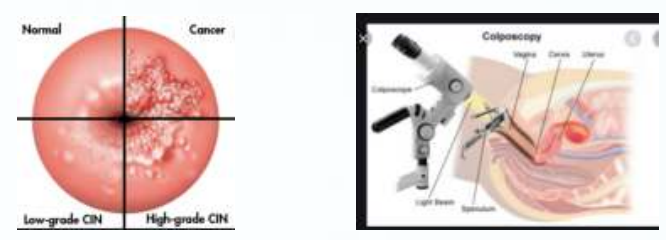

CervicalCheck is a free smear test offered to women aged 25 to 60 years and has been in operation in Ireland since 2008. Over the last ten years, it has provided three million smears to 1.8 million women, with over 280,000 women per year getting the test.

Over 1,480 cases of cervical cancer were notified to the CervicalCheck programme since 2008.

\section{Objectives}

Physicians can refer for colposcopy if concerned regarding a clinically suspicious cervix or a clinical history. In Ireland, in April 2018, a free smear test was offered to women who wished to avail of this outside the screening programme. This audit investigated the impact this had on referrals for a clinical indication and subsequent cancer diagnosis.

\section{Methods}

A retrospective review of referrals for a clinical indication from October 2017- February 2019 was conducted. The audit concentrated on referrals outside the routing screening programme. A search was conducted of referrals for suspicious cervix, post-menopausal bleeding, inter-menstral bleeding and post coital bleeding Referral data and outcomes was recorded from the mediscan system. Data was analysed using Microsoft Excel.

\section{Results}

Following the introduction of a free smear, the waiting time for non-urgent colposcopy rose from 4 weeks to $12-20$ weeks. The referrals for a 'clinical suspicion' rose from 79 in the first six months $(10 / 10 / 17-1 / 3 / 18)$ to 705 in the preceding six months.

\begin{tabular}{|l|l|l|l|l|}
\hline Referral Source & $\begin{array}{l}\text { Number (Total } \\
\text { 149) }\end{array}$ & $\%$ & Number(Total 741) & $\%$ \\
\hline College Dr & 1 & 1.26 & 3 & 0.42 \\
\hline Family planning & 3 & 3.79 & 20 & 2.83 \\
\hline GP & 46 & 58.22 & 590 & 83.8 \\
\hline GUM & - & - & 3 & 0.42 \\
\hline GOPD & 14 & 17.7 & 37 & 5.24 \\
\hline WWC & 3 & 3.79 & 18 & 2.55 \\
\hline Private rooms & 1 & 1.26 & 3 & 0.42 \\
\hline Other & 4 & 5.06 & 30 & 4.25 \\
\hline & & & & \\
\hline
\end{tabular}

\begin{tabular}{|l|l|l|l|l|}
\hline Referral cytology & Number & $\%$ & Number & $\%$ \\
\hline BNA & 2 & 1.81 & 33 & 5.22 \\
\hline $\begin{array}{l}\text { Glandular } \\
\text { neoplasia }\end{array}$ & & & & \\
\hline Inadequate & 1 & 0.9 & 12 & 1.89 \\
\hline $\begin{array}{l}\text { Mild dyskaryosis } \\
\begin{array}{l}\text { Moderate } \\
\text { dyskaryosis }\end{array}\end{array}$ & - & 7 & 1.10 \\
\hline $\begin{array}{l}\text { Severe } \\
\text { dyskaryosis }\end{array}$ & - & 4 & 0.63 \\
\hline No smear & 48 & 43.63 & 195 & 1.10 \\
\hline Normal & 57 & 57.8 & 338 & 30.8 \\
\hline
\end{tabular}

The number of referrals from GPs rose from $58 \%(n=46)$ to $83 \%$ $(n=590)$. The total number of cancers diagnosed following a clinical suspicious indication was eight (0.93). Two cases of cancer were diagnosed in the first six months $(2.53 \%)$, six were diagnosed in the preceding six months $(0.85 \%)$. Six cases of subsequently diagnosed cancer were referred and seen as urgent $(75 \%)$. Two cancers were diagnosed following a nonurgent referral. The majority of referrals had a normal colposcopy ( $n=29$ 36.5\%, 418 59.29\%).

\section{Conclusion}

Despite extra demand on the colposcopy department, the majority of subsequently diagnosed cancers were referred as urgent and seen promptly. The majority of clinically suspicious cervix resulted in a reassuring colposcopy

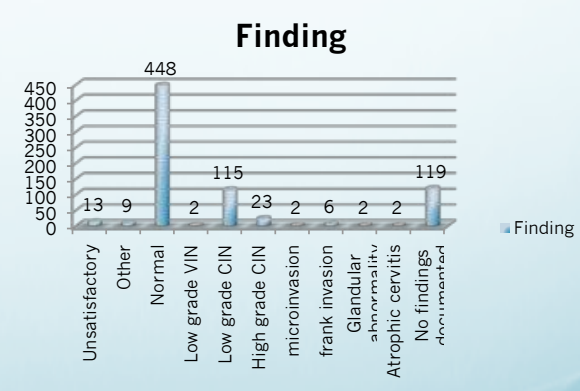

